\title{
Prevalence and clinical implication of adverse childhood experiences and their association with substance use disorder among patients with schizophrenia
}

\author{
Amira Mohamed Yousef ${ }^{{ }^{*}}$ (D), Amany Elshabrawy Mohamed ${ }^{1}$, Seham Mahmoud Eldeeb² and Rehab S. Mahdy ${ }^{1}$
}

\begin{abstract}
Background: Adverse childhood experiences (ACEs) and substance use disorder (SUD) are well-known risk factors for psychosis and dramatically affect schizophrenia. In this research, we aimed to measure the prevalence of adverse childhood experiences and substance use disorder in patients with schizophrenia and assess the effect of ACEs on the clinical presentation and overall functioning and the association between them and SUD in patients with schizophrenia. A cross-sectional study included a random sample of 165 schizophrenic patients who were examined by doing drug screen in urine, structured questionnaire to collect Socioeconomic characteristics, history of schizophrenia, structured clinical interview for Diagnostic and Statistical Manual of Mental Disorders-fifth edition, Positive and Negative Syndrome Scale (PANSS), Adverse Childhood Experiences International Questionnaire (ACE-IQ), World Health Organization Disability Assessment Schedule 2.0, compliance rating scale, addiction severity index fifth edition (ASI) for individuals with positive urine drug screen.

Results: Only $14.4 \%$ of the studied patients had no adverse childhood experiences. The prevalence of positive substance abuse screening was $18.2 \%$. There were statistically significant negative correlations between total ACE score and educational level, socioeconomic level, and the onset of schizophrenia. On the other hand, statistically significant positive correlations were found between the total ACE score and PANSS score and ASI score. The first most frequent ACE was significantly associated with female gender, lower education levels, low and middle socioeconomic classes, lifetime substance use, smokers, and positive drug screening. Emotional neglect and contact sexual abuse were significantly associated with positive drug screening. At the same time, Physical abuse was significantly associated with both lifetime substance use and positive drug screening.

Conclusion: The current study's findings indicate that childhood adverse experiences and substance abuse are prevalent problems in patients with schizophrenia. Given that there is an association between both issues, they may affect the symptomatology of the disorder, the prognosis, and the therapeutic plan. It is advised that a greater emphasis on and identification of childhood trauma and drug use disorder may be a necessary step in assessing patients with schizophrenia.
\end{abstract}

Keywords: Adverse childhood experiences, Substance abuse, Schizophrenia, Prevalence

\footnotetext{
*Correspondence: amira76@doctor.com

1 Psychiatry Department, Faculty of Medicine, Zagazig University, Zagazig, Egypt
}

Full list of author information is available at the end of the article

\section{Background}

Schizophrenia is a serious and persistent mental illness that affects around 20 million individuals worldwide. It is characterized by cognitive, perceptual, emotional, 
linguistic, and behavioral abnormalities. Hallucinations and delusions are frequently occurred. Its prevalence approaches $1 \%$ internationally. The incidence is about 1.5 per 10,000 people. Although schizophrenia can strike at any age, the typical age of onset for men is in their late teens to early twenties, and for women it is in their late twenties to early thirties. Schizophrenia is infrequent in children under the age of 12 or adults beyond the age of 40. Schizophrenia relates to significant impairment globally and can impair educational and occupational functioning. There is not a single element that has been established to cause schizophrenia via research. It is believed that schizophrenia is caused by an interplay between genes and a variety of environmental variables. Psychosocial variables may potentially play a role in the development of schizophrenia [1].

Over $69 \%$ of patients with schizophrenia do not receive adequate care, $90 \%$ of untreated schizophrenia patients live in low- and middle-income nations. Access to mental health care is a critical problem. Additionally, patients with schizophrenia seek care at a lower rate than the general population. Schizophrenia is a disorder that may be treated but requires lifelong treatment, even when symptoms have subsided. Medications are the cornerstone of schizophrenia treatment, and antipsychotic medications are the most prescribed drugs. Which include Second-generation antipsychotics, First-generation antipsychotics, and Long-acting injectable antipsychotics. The treatment modalities involve also Psychosocial interventions like Individual therapy, social skills training, Family therapy and Vocational rehabilitation and supported employment. Sometimes the patients need Hospitalization and Electroconvulsive therapy [2].

Schizophrenic patients are 2-3 times more likely than the general population to die prematurely. This is frequently the result of avoidable physical illnesses such as cardiovascular disease, metabolic disorders, and infection. People with schizophrenia frequently face stigma, discrimination, and violations of their human rights. Nearly $5 \%$ of schizophrenic people have a suicidal risk over their lifetime. Additionally, individuals with mental illnesses face a significantly elevated risk of accidental death, which is more likely than suicide [3].

A family history of schizophrenia, an older father, and autoimmune system abnormalities are among the risk factors for schizophrenia. Substance use disorders are a well-known risk factor for psychosis. According to the Epidemiologic Catchment Area study, 47\% of schizophrenia patients had significant drug or alcohol use problems over their lifetime compared to $16 \%$ of the general population. People with schizophrenia are more likely to have alcohol and cannabis use problems, with lifetime prevalence ranging from 21 to $86 \%$ for alcohol and 17 to 83\% for cannabis [4].

The risk of developing psychosis has long been linked to early childhood adverse experiences, characterized as physical or sexual violence, negligence, emotional abuse, injury, or fear of liability before 18 [5]. This correlation was discovered to be a dose-response interaction. For instance, exposure to more than four adverse experiences during childhood has been linked to a tenfold increased risk of developing schizophrenia [6].

Adverse childhood experiences (ACEs) may affect the brain, immune, and endocrine systems as they mature. Children who are used to a high degree of environmental stress are more likely to adopt risky behaviors like smoking, consuming alcohol, or engaging in antisocial behavior. This sets the individual on the road to poor adult health, putting them at risk for various diseases such as cancer, cardiovascular disease, hepatic disease, and pulmonary disease [7].

Indeed, emotional and physical maltreatment in childhood and sexual assault has been linked to an elevated risk of cigarette smoking, alcohol consumption, intake of an illegal substance, and polydrug abuse [8].

Furthermore, adolescent females who have experienced sexual abuse as children are about five times more expected to be heavily involved in polysubstance misuse than teenage girls who have not experienced sexual abuse as children [9].

While existing research has found that Adverse childhood experiences (ACEs) affect later-life health outcomes and these may be a risk factor for multiple psychiatric disorders like substance use disorder (SUD) and schizophrenia, little research has been done on this topic in Egypt on such a vulnerable group of patients with schizophrenia. This gap in the research is alarming given the effects of adverse childhood experiences have been shown in developing countries [10]. This is a crucial topic ripe for further investigation. As the youth represent more than one-third of the Egyptian people, it emphasizes the importance of safe families and adequate childrearing environments.

In this research, we aimed to measure the prevalence of Adverse Childhood Experiences and substance use disorder and detect the association between them in patients with schizophrenia and their effect on the clinical presentation and overall functioning in those patients.

\section{Methods}

A cross-sectional study was performed from March to July 2019 on patients with schizophrenia at the psychiatric ward and the outpatient clinic of The University Hospital. 
This study enrolled a random sample of 165 patients with schizophrenia after obtaining written informed consent from all of them.

Patients had to meet the following inclusion criteria to fulfill Diagnostic and Statistical Manual of Mental Disorders-fifth edition (DSM-5) criteria for schizophrenia, be 18 years or older, both genders, and all socioeconomic classes. Exclusion criteria included the following: patients with (acute psychotic episodes, comorbid psychiatric disorder other than SUD), and rejection to sign the consent.

The sample size was measured by assuming that the total number of patients with schizophrenia attending the psychiatric department of The University Hospital in 12 months is 288 patients. The prevalence of substance use disorder in schizophrenic patients is $50 \%$. At a confidence level of $95 \%$, the sample size in 165 patients. It was calculated by Open Epi [11].

Interviews were conducted, Face-to-face to collect data by the researchers. Patients from the psychiatric ward were interviewed upon discharge when their symptoms become stabilized (those patients did not have electroconvulsive therapy (ECT) during their admission in the psychiatric ward), while patients from the outpatient clinic were interviewed at their follow-up visits.

A structured questionnaire was used. It included the Socioeconomic characteristics measured by the scale for assessing family socioeconomic status (SES) for medical studies in Egypt [12]. It is a previously validated, structured scale with an internal consistency of 0.66 (Cronbach's alpha coefficient). Also, it included the history of the schizophrenic disorder, which involved the age of onset, duration of illness, family history, number of hospitalizations, medical history, consanguinity, tobacco smoking, and lifetime and current substance use (types of drugs, age of first drug abuse, duration of drug abuse, Abstinence, and hospitalization due to drug addiction).

The Structured Clinical Interview for SCID-5 -RV (Research Version) was applied to confirm the diagnosis of schizophrenia and substance use disorder. The SCID5-RV for DSM-5 was released in 2016 and includes the DSM5 primary diagnoses, also involves more disorders with all associated subtypes, severity, and course specifiers than the clinician version. It's used when the range of diagnoses covered in the Structured Clinical Interview for SCID-5 clinician version (SCID-5-CV) is insufficient (for example the assessment of certain disorders of interest are required but omitted from the SCID-5-CV, such as eating disorders), Also If the study requirements include making modifications such as, altering diagnostic time frames which we needed in our research. SCID 5 contains another two versions for personality disorders [13].
Positive and Negative Syndrome Scale (PANSS) was used to measure the symptoms' severity. The PANSS is a standard psychiatric interview that assesses the occurrence and severity of positive and negative manifestations and general psychopathology of individuals who have recently been diagnosed with schizophrenia. It includes 30 items, Seven items for positive symptoms, seven for negative symptoms, and sixteen for general psychopathology symptoms. The severity of each item is determined by which anchoring points on a seven-point scale ( $1=$ absent; $7=$ extreme) better characterize the symptom's presentation. In each of the subscales, elevated scores indicate more severity [14].

Adverse Childhood Experiences International Questionnaire (ACE-IQ) (Arabic version) was used [15]. It was created by research teams from the (WHO), the Centers for Disease Control and Prevention, and international expertise. It was translated into Arabic and then back into English, with the vocabulary changed to be culturally adaptable. Additionally, it was pilot tested in the Kingdom of Saudi Arabia previously. The ACE-IQ questions address physical, sexual, and emotional assault and negligence by parents or caregivers; peer aggression; family discord (violence against household members; living with drug addicts, mentally disturbed, suicidal, or jailed household individuals, having one or no parents, divorce of the parents); and experiencing societal aggression and susceptibility to collective violence. For the current study, we did not involve the questions related to experiencing societal aggression and exposure to communal violence as these issues are not prevalent in Egypt. The questions regarding ACEs were binary and assessed the individuals' first 18 years of life. The number of ACEs mentioned by respondents was calculated to produce the total ACE score (range 0-12).

Compliance Rating Scale (CRS) [16]. On a seven-point scale, the CRS is used to rate drug adherence. Patients who reject treatment entirely receive a one-star rating, while those who partly refuse a two-star rating. Patients who reluctantly or passively accept treatment receive a three-, four-, or five-star rating, while those who reasonably or actively consider treatment receive a six- or seven-rating. The questionnaire includes a summary of compliance behavior for each score.

World Health Organization Disability Assessment Schedule 2.0 (WHODAS 2.0) was used [17]. It includes twelve items. Impairment and disability were measured across 6 preceding months: cognition, mobility, self-care, social interaction, and interest in life and community practices. The items are graded on a five-point Likert scale, with 1 representing the absence of disability and 5 representing significant disability or incapacity to conduct a particular task. A cumulative disability score is 
calculated by combining the scores, with higher scores indicating more severe disability. The WHODAS were validated in Schizophrenia patients. An internal consistency of 0.78 (Cronbach's alpha coefficient) [18].

Addiction Severity Index (ASI) fifth edition (Arabic version) was used for individuals with positive urine drug screen [19]. It is a multidimensional interview that assesses the substance use, general condition, and social difficulties in individuals who have alcohol or other addiction issues, both during treatment and subsequent follow-up. It is intended to assess patient status across seven functional categories: alcohol and substance use, physical and mental wellbeing, work, support, family relationships, and illegal activity. ASI is translated into Arabic and validated by Qassem et al. (2004) in the Institute of Psychiatry, Ain-Shams University Hospitals [20].

Drug Screen in urine: Urine specimens were collected in clean and dry plastic containers at room temperature. We used the Multi-Drug One Step Screen Test Panel (Urine), a lateral flow chromatographic immunoassay for the qualitative detection of the following four drugs: (Tetrahydrocannabinol, Opiates, Tramadol, Benzodiazepines).

Statistical analysis was done using SPSS Statistics for Windows, Version 27. IBM Corp. 2020 [21]. Data were presented in tables and a figure. We used the mean, median, standard deviation, and range for giving Quantitative variables. Qualitative variables were shown as frequencies and proportions. To analyze qualitative data, we used Pearson's chi-square $\left(\chi^{2}\right)$ test. When appropriate, Student's $t$-test (T) and Mann Whitney test (MW) were used to analyze continuous data between two groups. But we used Kruskal-Wallis $\mathrm{H}(\mathrm{KW})$ tests to analyze continuous data between more than two groups. To find the correlation between continuous variables, Spearman's correlation coefficient $(r)$ was used. In all tests, a $P$-value of ${ }^{<} 0.05$ was accepted as statistically significant.

\section{Results}

The studied patients had a mean age of 35.5 years old, $80.0 \%$ were males, $49.7 \%$ were single, $35.2 \%$ had secondary education, $78.2 \%$ were none working, $70.9 \%$ were rural residents, $44.8 \%$ were low socioeconomic class, the mean age of onset of schizophrenia was 22.8 years old, mean duration of disease was 13.2 years, $40.6 \%$ were hospitalized once, the prevalence of lifetime substance use was $41.2 \%$, 45.5\% were smokers, mean PANSS positive was 16.2, mean PANSS negative was 17.5, mean PANSS general was 33.7, mean Compliance Rating Scale was 4.5, and the mean simple score of WHODAS was 32.5. Positive substance abuse screening prevalence in the studied patients was $18.2 \%$ (Table 1 ).
Table 1 Socio-demographic and psychiatric characteristics of the studied patients

\begin{tabular}{|c|c|}
\hline Variables & $\begin{array}{l}\text { Studied } \\
\text { patients } \\
(n=165)\end{array}$ \\
\hline \multicolumn{2}{|l|}{ Age (years) } \\
\hline Mean $\pm S D$ & $35.5 \pm 9.7$ \\
\hline \multicolumn{2}{|l|}{ Gender } \\
\hline Males & $132(80.0 \%)$ \\
\hline Females & $33(20.0 \%)$ \\
\hline \multicolumn{2}{|l|}{ Marital status } \\
\hline Single & $82(49.7 \%)$ \\
\hline Married & $52(31.5 \%)$ \\
\hline Divorced & $25(15.2 \%)$ \\
\hline Widowed & $6(3.6 \%)$ \\
\hline \multicolumn{2}{|l|}{ Education } \\
\hline Illiterate, read and write & $11(6.7 \%)$ \\
\hline Primary education & $12(7.3 \%)$ \\
\hline Preparatory education & $33(20.0 \%)$ \\
\hline Secondary education & $58(35.2 \%)$ \\
\hline High education & $51(30.9 \%)$ \\
\hline \multicolumn{2}{|l|}{ Occupation } \\
\hline Working & $36(21.8 \%)$ \\
\hline Not working & $129(78.2 \%)$ \\
\hline \multicolumn{2}{|l|}{ Residence } \\
\hline Urban & $48(29.1 \%)$ \\
\hline Rural & $117(70.9 \%)$ \\
\hline \multicolumn{2}{|l|}{ Socio-economic level } \\
\hline Low & $74(44.8 \%)$ \\
\hline Middle & $52(31.5 \%)$ \\
\hline High & $39(23.6 \%)$ \\
\hline \multicolumn{2}{|c|}{ Age of onset of schizophrenia (years) } \\
\hline Mean \pm SD & $22.8 \pm 6.7$ \\
\hline \multicolumn{2}{|l|}{ Duration of disease (years) } \\
\hline Mean \pm SD & $13.2 \pm 8.7$ \\
\hline \multicolumn{2}{|l|}{ Frequency of hospitalization } \\
\hline None & $24(14.5 \%)$ \\
\hline Once & $67(40.6 \%)$ \\
\hline Twice & $52(31.5 \%)$ \\
\hline More than twice & $22(13.4 \%)$ \\
\hline \multicolumn{2}{|l|}{ Lifetime substance use } \\
\hline Positive & $68(41.2 \%)$ \\
\hline Negative & $97(58.8 \%)$ \\
\hline \multicolumn{2}{|l|}{ Smoking status } \\
\hline Not smoker & $58(35.2 \%)$ \\
\hline Ex-smoker & $17(10.3 \%)$ \\
\hline Smoker & $90(45.5 \%)$ \\
\hline \multicolumn{2}{|l|}{ PANSS (mean $\pm S D$ ) } \\
\hline Positive & $16.2 \pm 5.4$ \\
\hline Negative & $17.5 \pm 5.8$ \\
\hline General & $33.7 \pm 11.6$ \\
\hline Compliance Rating Scale (CRS) & \\
\hline
\end{tabular}


Table 1 (continued)

\begin{tabular}{ll}
\hline Variables & $\begin{array}{l}\text { Studied } \\
\text { patients } \\
(\boldsymbol{n}=\mathbf{1 6 5 )}\end{array}$ \\
\hline $\begin{array}{l}\text { Mean } \pm S D \\
\text { WHODAS (simple score) } \\
\text { Mean } \pm \text { SD }\end{array}$ & $4.5 \pm 1.3$ \\
$\begin{array}{l}\text { Drug screen results } \\
\text { Positive }\end{array}$ & $32.5 \pm 10.8$ \\
$\quad$ Negative & $30(18.2 \%)$ \\
\hline SD standard deviation & $135(80.8 \%)$ \\
\hline
\end{tabular}

Table 2 Adverse childhood experiences in the studied patients

\begin{tabular}{llc}
\hline ACE categories & \multicolumn{2}{l}{$\begin{array}{l}\text { Studied } \\
\text { patients } \\
(\boldsymbol{n}=\mathbf{1 6 5})\end{array}$} \\
\cline { 2 - 3 } & No. & $\%$ \\
\hline Mother and/or household member treated violently & 100 & 60.6 \\
Emotional neglect & 66 & 40.0 \\
Physical abuse & 42 & 25.5 \\
Contact sexual abuse & 37 & 22.4 \\
Someone chronically depressed, mentally ill, institu- & 34 & 20.6 \\
tionalized or suicidal & & \\
One or no parents, parental separation or divorce & 31 & 18.8 \\
Emotional abuse & 29 & 17.6 \\
Physical neglect & 25 & 15.2 \\
Community violence & 24 & 14.5 \\
Bullying & 18 & 10.9 \\
Alcohol and/or drug abuser in the household & 13 & 7.9 \\
Incarcerated household member & 5 & 3.0 \\
Total ACE score & & \\
$\quad$ Mean \pm SD & $3.7 \pm 2.5$ & \\
\hline
\end{tabular}

$A C E$ adverse childhood experiences; SD standard deviation

The most frequent adverse childhood experiences were the mother or household member being treated violently (60.6\%), emotional neglect $(40.0 \%)$, physical abuse (25.5\%), and contact sexual abuse (22.4\%). The mean ACE score (binary version) was 3.7 (Table 2).

Only $14.4 \%$ of the studied patients had zero ACE. This means that $85.6 \%$ of the studied patients had at least one ACE. Almost one-quarter of the studied patients had $\geq 4$ ACEs (Fig. 1).

Among the screening positive patients, $76.7 \%$ were positive for cannabis only, and the rest were positive for both cannabis and tramadol. $83.3 \%$ had a daily intake of the addicted substance, mean age of onset of substance use was 19.8 years old, mean duration of substance use was 10.6 years, 63.3\% reported Abstinence,
13.3\% reported hospitalization due to substance use. The median addiction severity index was 28.5 (Table 3, Fig. 2).

There were statistically significant negative correlations between total ACE score and educational level, socioeconomic level, and age of onset of schizophrenia (Table 4). On the other hand, statistically significant positive correlations between total ACE score and PANSS positive and addiction severity index.

There were statistically significant associations between ACE type and characteristics of the studied patients (Table 5). The first most frequent ACE (Mother or Household member treated violently) was significantly associated with female gender (87.9\%), education level other than high education (73.9\%, 72.7\%, 70.7\%), low and middle socioeconomic classes $(77.0 \%, 61.5 \%)$, lifetime substance use $(75.0 \%)$, smokers $(85.6 \%)$ and positive drug screening (80.0\%).

Emotional neglect was significantly associated with low and preparatory education $(82.6 \%, 75.8 \%)$, low socioeconomic class (58.1\%), smokers and ex-smokers (46.7\%, $58.8 \%)$, and positive drug screening (63.3\%).

Physical abuse was significantly associated with divorced patients (72.0\%), low and preparatory education $(60.9 \%, 63.6 \%)$, rural residents $(29.9 \%)$, lifetime substance use (50.0\%), and positive drug screening (43.3\%).

Contact sexual abuse was significantly associated with female gender (57.6\%), low and preparatory education $(39.1 \%, 42.4 \%)$, rural residents $(28.2 \%)$, low socioeconomic class (31.1\%), and positive drug screening (36.7\%).

\section{Discussion}

Adverse childhood experiences (ACEs) have been attributed to harmful health behaviors and the risk of chronic diseases in adulthood. This research investigated the relationship between ACEs and substance use disorders in patients with schizophrenia. In the current study, only $14.4 \%$ of the studied patients had zero ACE. This means that $85.6 \%$ of the studied patients had at least one ACE. Almost one-quarter of the studied patients had $\geq 4$ ACEs.

In line with our study, Schalinski et al. (2017) found that $80.5 \%$ of patients with schizophrenia had at least one type of childhood trauma, and $48.9 \%$ had more than two types of traumas. In addition, $18.3 \%$ and $13.3 \%$ had one and two types of traumas, respectively, while $19.4 \%$ of Schizophrenia patients had no ACE [22].

On the other hand, Andrianarisoa et al. (2017) reported a high prevalence of childhood trauma (82.5\%) among schizophrenic patients [23]. This high prevalence can be explained because even mild childhood trauma was included in the childhood trauma group.

The frequency of childhood adverse experiences in patients with schizophrenia varied across the studies 


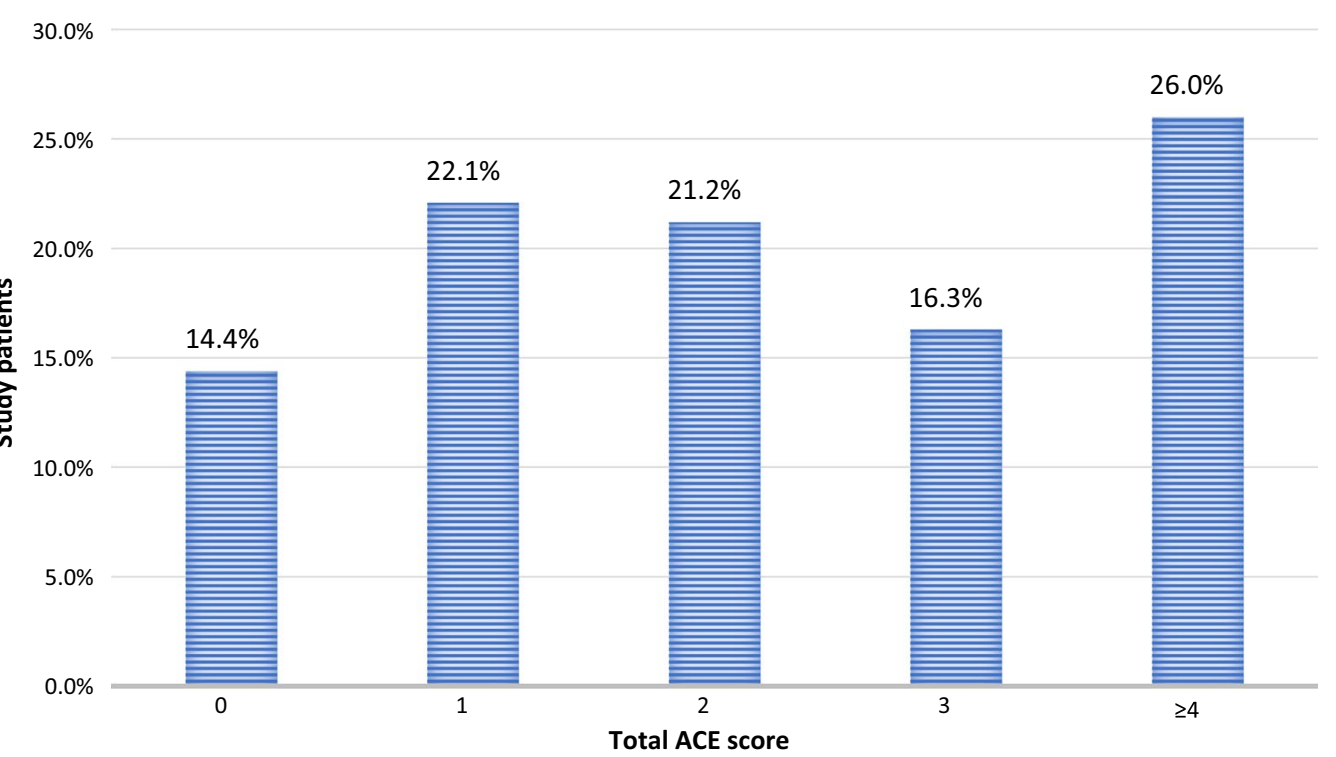

Fig. 1 Frequency distribution of the studied patients according to total ACE score. ACE Adverse Childhood Experiences International Questionnaire

Table 3 Frequency distribution of drug screen positive patients according to their substance use disorder

\begin{tabular}{ll}
\hline Variables & $\begin{array}{l}\text { Drug screen } \\
\text { positive patients } \\
(\boldsymbol{n}=30)\end{array}$ \\
\hline $\begin{array}{l}\text { Type of drug } \\
\text { Cannabis }\end{array}$ & $23(76.7 \%)$ \\
$\quad$ Cannabis, Tramadol & $7(23.3 \%)$ \\
Frequency & \\
$\quad$ Daily & $25(83.3 \%)$ \\
$\quad$ Weekly & $5(16.7 \%)$ \\
Age of onset of substance use & \\
$\quad$ Mean \pm SD & $19.8 \pm 4.6$ \\
Duration of substance use (years) & \\
$\quad$ Mean \pm SD & $10.6 \pm 3.9$ \\
Abstinence & \\
$\quad$ Yes & $19(63.3 \%)$ \\
$\quad$ No & $11(36.7 \%)$ \\
Hospitalization due to substance use & \\
Yes & \\
No & \\
Addiction severity index & $(13.3 \%)$ \\
Mean $\pm S D$ & $26(86.7 \%)$ \\
\hline SD standard deviation & \\
\end{tabular}

[24-28]. It ranged from 50 to $94 \%$. The disparities may be attributed to various reasons, including diverse demographics, multiple decades of assessment, disparate scales for evaluating childhood trauma, recall bias, sample size, and different countries and cultures. Additionally, other

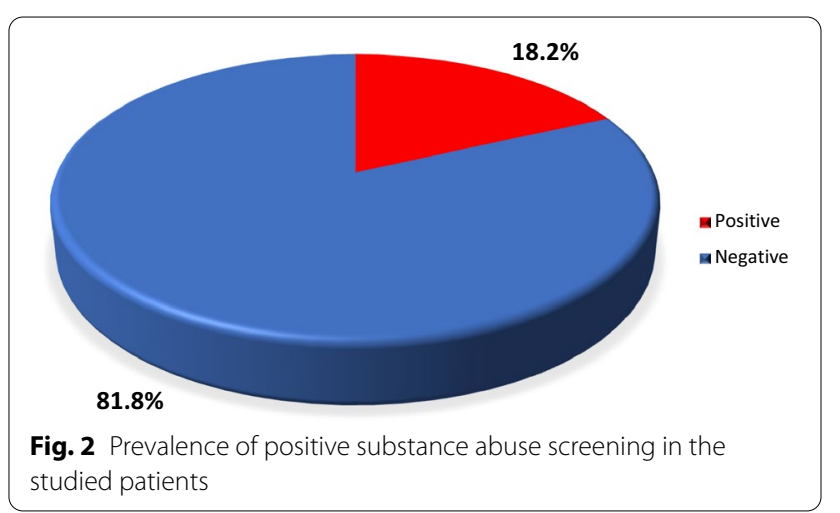

demographic characteristics may clarify the higher childhood trauma rates because childhood trauma questionnaires examine various experiences, the majority of which are linked to social status and educational level.

In the present study, the most frequent adverse childhood experiences were the mother, or household member treated violently (60.6\%), emotional neglect (40.0\%), physical abuse (25.5\%), and contact sexual abuse (22.4\%).

In a study of male patients with schizophrenia, the most often reported subtype of the adverse incident was psychiatric illness among family members (72.5\%), followed by the separation, divorce, or mortality of the parents $(58.8 \%)$, emotional negligence $(54.9 \%)$, and physical neglect (43.6\%). Sexual abuse and imprisonment of a family member were uncommon $(19.6 \%$ and $29 \%$, respectively) [27].

In a study of adults with Schizophrenia, Rosenberg et al. (2007) found that the most common form of 
Table 4 Correlation between total ACE score and other variables in the studied patients

\begin{tabular}{lcl}
\hline Variables & \multicolumn{2}{l}{ Total ACE score } \\
\cline { 2 - 3 } & $\boldsymbol{r}$ & $\boldsymbol{P}$ \\
\hline Age & 0.001 & 0.9 \\
Educational level & -0.28 & $0.01^{*}$ \\
Socio-economic level & -0.32 & $0.005^{*}$ \\
Age of onset of schizophrenia & -0.24 & $0.02^{*}$ \\
Duration of disease & -0.11 & 0.3 \\
Frequency of hospitalization & 0.17 & 0.1 \\
PANSS positive & 0.28 & $0.001^{*}$ \\
PANSS negative & 0.06 & 0.5 \\
PANSS general & 0.06 & 0.5 \\
Compliance Rating Scale (CRS) & -0.02 & 0.8 \\
WHODAS (simple score) & 0.08 & 0.4 \\
Age of onset of substance & 0.03 & 0.9 \\
Duration of substance use & 0.11 & 0.3 \\
Addiction severity index & 0.21 & $0.04^{*}$ \\
\hline
\end{tabular}

ACE adverse childhood experiences; PANSS Positive and Negative Syndrome Scale; WHODAS World Health Organization Disability Assessment Schedule; CRS Compliance Rating Scale

*Statistically significant

adverse childhood event was child physical abuse (56\%), followed by witnessing domestic violence (49\%), parental separation, or divorce (36\%), child sexual abuse (34\%), and parental mental illness (21\%) [28].

A meta-analysis study by Read et al. (2005) reported that psychotic patients had a high prevalence of childhood sexual and physical abuse. Sexual abuse was $48 \%$ among females and $28 \%$ among males. Physical abuse was $48 \%$ among females and 50\% among males [6]. In addition, other pieces of literature reported that emotional abuse and neglect are more common in schizophrenia than physical abuse or neglect [25, 29-32].

We may explain the high prevalence of domestic violence in Egypt that violent behavior is typical against wives, especially in low socioeconomic status and a widely accepted cultural practice compared to highincome countries. Besides, the prevalence of recorded sexual abuse is somewhat lower in this study, primarily due to societal taboos and shame associated with child sexual abuse.

The current study found statistically significant negative correlations between total ACE score, educational level, and socioeconomic level. In agreement with the present study, Alvarez et al. (2011) and Schenkel et al. (2005) and found an association between childhood trauma and lower educational level, history of school difficulty, and these findings are similar to our results $[8$, 33].
In contrast, Vallejos et al. (2017) and Rosenberg et al. (2007) found no statistically significant difference in the level of education among patients who suffered multiple adverse events [27, 28]. A study done by Gil et al. (2009) showed that childhood trauma had no association with sociodemographic variables [34].

The current study found statistically significant negative correlations between total ACE score and age of onset of schizophrenia. These findings were in line with other literature [22, 25, 35-38]. The start of schizophrenia was earlier if the patients had been subjected to adverse childhood experiences. This result was significant only in cases of physical abuse within the abuse-specific subgroups [39].

Another study revealed that patients with a history of abuse, regardless of gender, have a significantly younger age of onset. In contrast, physical trauma appears to be a critical factor in accelerating the onset of schizophrenia, particularly in females [40]. In comparison, Rajkumar (2015) reported that age of onset was not correlated with the ACE scores [29].

There were statistically significant positive correlations between total ACE score and PANSS positive. In contrast, Longden et al. (2016) found a significant correlation between childhood trauma with positive symptoms and negative symptoms of schizophrenia. This difference from our study can be explained by studying the effect of different categories of childhood adversities on negative symptoms. This significant correlation is found with physical and emotional abuse only [41].

The current study found no statistically significant correlation between ACE score and WHODAS simple score. In agreement with our results, Rajkumar (2015) and Duhig et al. (2015) found that there was no significant relationship between childhood trauma and social, vocational, or overall functioning $[29,30]$.

On the other hand, Baudin et al. (2016), Gil et al. (2009), and Rosenberg et al. (2007) found that childhood trauma had an association with increased disability in adulthood presented by a statistically significant negative correlation between childhood trauma and overall functioning [34, 42]. This variation can be explained by different methodologies. Using the WHO Disability Assessment Scale criteria, impairment refers to interference in one's ability to function in six domains: cognition, mobility, self-care, getting along, life activities, and community participation.

Our study showed that there is no statistically significant correlation between ACE and medication adherence. In contrast, Lecomte et al. (2008) found that patients exposed to childhood trauma had lower compliance with treatment [43]. It can be explained by the presence of different variables influencing medication 
Table 5 Association between common adverse childhood experiences and characteristics of the studied patients

\begin{tabular}{|c|c|c|c|c|}
\hline Variables & $\begin{array}{l}\text { Mother and/or household } \\
\text { member treated violently }\end{array}$ & Emotional neglect & Physical abuse & Contact sexual abuse \\
\hline \multicolumn{5}{|l|}{ Gender } \\
\hline Males $(n=132)$ & $71(53.8 \%)$ & $54(40.9 \%)$ & $36(27.3 \%)$ & $18(13.6 \%)$ \\
\hline Females $(n=33)$ & $29(87.9 \%)$ & $12(36.4 \%)$ & $6(18.2 \%)$ & $19(57.6 \%)$ \\
\hline$P$-value & $<0.001^{*}$ & 0.6 & 0.3 & $<0.001^{*}$ \\
\hline \multicolumn{5}{|l|}{ Marital status } \\
\hline Single $(n=82)$ & $44(53.7 \%)$ & $29(35.4 \%)$ & $12(14.6 \%)$ & $22(26.8 \%)$ \\
\hline Married $(n=52)$ & $32(61.5 \%)$ & $22(42.3 \%)$ & $12(23.1 \%)$ & $8(15.4 \%)$ \\
\hline Divorced $(n=25)$ & $18(72.0 \%)$ & $11(44.0 \%)$ & $18(72.0 \%)$ & $6(24.0 \%)$ \\
\hline Widowed $(n=6)$ & $6(100 \%)$ & $4(66.7 \%)$ & $0(0.0 \%)$ & $1(16.7 \%)$ \\
\hline$P$-value & 0.07 & 0.4 & $<0.001^{*}$ & 0.5 \\
\hline \multicolumn{5}{|l|}{ Education } \\
\hline Low education $(n=23)$ & $17(73.9 \%)$ & $19(82.6 \%)$ & $14(60.9 \%)$ & $9(39.1 \%)$ \\
\hline Preparatory education $(n=33)$ & $24(72.7 \%)$ & $25(75.8 \%)$ & $21(63.6 \%)$ & $14(42.4 \%)$ \\
\hline Secondary education $(n=58)$ & $41(70.7 \%)$ & $20(34.5 \%)$ & $5(8.6 \%)$ & $8(13.8 \%)$ \\
\hline High education $(n=51)$ & $18(35.3 \%)$ & $2(3.9 \%)$ & $2(3.9 \%)$ & $6(11.8 \%)$ \\
\hline$P$-value & $<0.001^{*}$ & $<0.001^{*}$ & $<0.001^{*}$ & $<0.001^{*}$ \\
\hline \multicolumn{5}{|l|}{ Occupation } \\
\hline Working $(n=36)$ & $18(50.0 \%)$ & $15(41.7 \%)$ & $9(25.0 \%)$ & $9(25.0 \%)$ \\
\hline Not working $(n=129)$ & $82(63.6 \%)$ & $51(39.5 \%)$ & $33(25.6 \%)$ & $28(21.7 \%)$ \\
\hline$P$-value & 0.1 & 0.8 & 0.9 & 0.7 \\
\hline \multicolumn{5}{|l|}{ Residence } \\
\hline Urban $(n=48)$ & $8(21.1 \%)$ & $14(29.2 \%)$ & $7(14.6 \%)$ & $4(8.3 \%)$ \\
\hline Rural $(n=117)$ & $92(78.6 \%)$ & $52(44.4 \%)$ & 35 (29.9\%) & $33(28.2 \%)$ \\
\hline$P$-value & $<0.001^{*}$ & 0.07 & $0.04^{*}$ & $0.005^{*}$ \\
\hline \multicolumn{5}{|l|}{ Socio-economic level } \\
\hline Low $(n=74)$ & $57(77.0 \%)$ & $43(58.1 \%)$ & $21(28.4 \%)$ & $23(31.1 \%)$ \\
\hline Middle $(n=52)$ & $32(61.5 \%)$ & $16(30.8 \%)$ & $11(21.2 \%)$ & $8(15.4 \%)$ \\
\hline High $(n=39)$ & $11(28.2 \%)$ & $7(17.9 \%)$ & $10(25.6 \%)$ & $6(15.4 \%)$ \\
\hline$P$-value & $<0.001^{*}$ & $<0.001^{*}$ & 0.07 & $0.05^{*}$ \\
\hline \multicolumn{5}{|l|}{ Lifetime substance use } \\
\hline Positive $(n=68)$ & $51(75.0 \%)$ & $30(44.1 \%)$ & $34(50.0 \%)$ & $14(20.6 \%)$ \\
\hline Negative $(n=97)$ & $49(50.5 \%)$ & $36(37.1 \%)$ & $8(8.3 \%)$ & $23(23.7 \%)$ \\
\hline$P$-value & $0.002^{*}$ & 0.4 & $<0.001^{*}$ & 0.6 \\
\hline \multicolumn{5}{|l|}{ Smoking status } \\
\hline Not smoker $(n=58)$ & $12(20.7 \%)$ & $14(24.1 \%)$ & $16(27.6 \%)$ & $15(25.9 \%)$ \\
\hline Ex-smoker $(n=17)$ & $11(64.7 \%)$ & $10(58.8 \%)$ & $7(41.2 \%)$ & $6(35.3 \%)$ \\
\hline Smoker $(n=90)$ & $77(85.6 \%)$ & $42(46.7 \%)$ & $19(21.1 \%)$ & $16(17.8 \%)$ \\
\hline$P$-value & $<0.001^{*}$ & $0.006^{*}$ & 0.2 & 0.2 \\
\hline \multicolumn{5}{|l|}{ Drug screen results } \\
\hline Positive $(n=30)$ & $24(80.0 \%)$ & $19(63.3 \%)$ & $13(43.3 \%)$ & $11(36.7 \%)$ \\
\hline Negative $(n=135)$ & $76(56.3 \%)$ & $47(34.8 \%)$ & $29(21.5 \%)$ & $26(19.3 \%)$ \\
\hline$P$-value & $0.01^{*}$ & $0.003^{*}$ & $0.01^{*}$ & $0.03^{*}$ \\
\hline
\end{tabular}

*Statistically significant

adherence. A robust familial support system following the first hospitalization has been found to deflect the impact of social and internalized stigma. Therefore, it can lead to a quicker recovery with greater ease in following treatment guidelines. Personal beliefs and attitudes about medication and psychiatric services have influenced treatment adherence and can be modified using cognitive-behavioral strategies. Also, specific 
personality traits, primarily being high in agreeableness, were linked to poor medication adherence. It can also be connected to a higher likelihood of being influenced by peers and eagerness to be accepted in a group and avoid social rejection linked to psychosis.

The current study found no statistically significant correlation between ACE score and frequency of hospitalization, which was consistent with other studies $[22,27]$. In contrast, some studies revealed that a history of childhood abuse was associated with a more significant number of previous hospitalizations and earlier at first hospitalization [28, 33]. These findings may be explained by patients having difficulties recalling this detail since most participants in this study had been treated for several years; they could also be explained by subjects choosing not to share particular events, experiences, or personal behaviors [44].

The current study found statistically significant associations between the type of ACE and the characteristics of the studied patients. Yildirim et al. (2014) found that patients with primary school education were higher in patients with emotional neglect history [37]. Rajkumar. (2015) found that Childhood trauma was unrelated to one's childhood residence (rural or urban) and had no statistically significant correlation with overall years of education. And these findings were different from our findings [29]. Our result may be explained that rural areas have a lower social status and education level than towns. Thus, parents are preoccupied with earning a living and lack the time necessary to provide for their children, raising the likelihood of feeling neglected by their parents.

The prevalence of positive substance abuse screening in the studied patients was $18.2 \%$. Almost threequarters of them were positive for cannabis only, and the rest were positive for both cannabis and tramadol. There were statistically significant positive correlations between total ACE score and addiction severity index.

These results were consistent with Lasalvia et al. (2012), who found that $20.3 \%$ of schizophrenic patients were positive for substance abuse, and the most used drug was cannabis [45].

Besides, Margolese et al. (2004) found that $44.9 \%$ of schizophrenic patients fulfilled the criteria for lifelong drug misuse, and $14.0 \%$ fulfilled the criteria for current abuse/dependence and reported that the most often consumed drugs were alcohol and cannabis [46].

According to an Egyptian study by Asaad et al. (2003), $26 \%$ of schizophrenic patients met DSM-5 guidelines for drug misuse. Anti-parkinsonian medications were the most often abused substance, followed by cannabinoids, opioids, and benzodiazepines [47].
On the other hand, Swartz et al. (2006) incorporated radioimmunoassay of hair specimens and urine drug tests into diagnostic assessments combined with selfreport measures. They reported that $37 \%$ of patients were diagnosed as having current substance use disorder [48].

The wide variance of the comorbid substance abuse prevalence in schizophrenia is based on the diagnostic evaluation techniques used, the presence of collateral informants, and the laboratory assessment techniques. Also, the high prevalence of alcohol misuse in western countries, which was not measured in this study, may lead to a high prevalence of substance use in other studies. Another cause for this variance is different cultures and legal constraints across countries.

Limitations: The cross-sectional design used by this study made it difficult to disentangle the effect of substance; for example, cannabis may result in psychotic experiences, but psychotic experiences may also result in the individual using cannabis to reduce the incidents of psychosis. So future longitudinal studies need to be done.

History of childhood trauma may also be associated with other co-morbidities, including post-traumatic stress disorder (PTSD), which may be targeted by specific psychotherapies, such as trauma-focused cognitive behavioral therapy. PTSD has not been evaluated in the present study, which is a clear limit and should be considered in further studies.

Our study lacked a control group, and we are therefore unable to comment on whether the patients in our sample experienced higher levels of childhood trauma or substance abuse than appropriately matched controls from the same population.

\section{Conclusion}

Finally, the current study's findings indicate that childhood adverse experiences and substance abuse are prevalent problems in patients with schizophrenia. Given the association between both issues, they may affect the symptomatology of the disorder, the prognosis, and the therapeutic plan. It is advised that a greater emphasis on and identification of childhood trauma and drug use disorder may be a necessary step in assessing patients with schizophrenia. Further studies were needed using analytical design and larger sample sizes. More research is required to document better the link between ACEs and overall health and wellbeing in Egypt.

\footnotetext{
Abbreviations

ACE-IQ: Adverse Childhood Experiences International Questionnaire; WHODAS 2.0: World Health Organization Disability Assessment Schedule 2.0; APA: American Psychiatric Association; ASI: Addiction Severity Index; CRS: Compliance Rating Scale; DSM-5: Diagnostic and Statistical Manual of Mental Disordersfifth edition; ECT: Electroconvulsive therapy; MW: Mann Whitney test; PANSS: Positive and Negative Syndrome Scale; r: Correlation coefficient; SCID-5 -RV:
} 
Structured Clinical Interview for DSM-5 (Research Version); SD: Standard deviation; SPSS: Statistical Package for Social Science; SUD: Substance use disorder; $t$ : Student's t-test; THC: Tetrahydrocannabinol; WHO: World Health Organization; WHODAS 2.0: World Health Organization Disability Assessment Schedule 2.0; $x^{2}$ : Chi-square test.

\section{Acknowledgements}

The authors would like to thank all the study participants.

\section{Authors' contributions}

AY designs the work, drafts the article and substantively revised it. AE acquisition of data and shared in the drafting of the article. RM shared in analysis, interpretation of data and the drafting of the article. SE shared in analyzing the data and did the statistical analysis. All authors read and approved the final manuscript.

\section{Funding}

The authors declare that they have no funding support.

\section{Availability of data and materials}

Not applicable.

\section{Declarations}

\section{Ethics approval and consent to participate}

Official permissions were obtained from Institutional Review Board at the Faculty of Medicine, Zagazig University hospitals with Reference Number (ZU-IRB\#5056) on 6-1-2019, and the Psychiatry Department same University. A written informed consent was obtained from all participants, and they had the right to withdraw from the study at any time and without negatively affecting their medical care. The results of this study could be used as a scientific publication, but the participant's identity will be confidential.

\section{Consent for publication}

Not applicable.

\section{Competing interests}

The authors declare that they have no competing interests.

\section{Author details}

'Psychiatry Department, Faculty of Medicine, Zagazig University, Zagazig, Egypt. ${ }^{2}$ Public Health and Community Medicine, Faculty of Medicine, Zagazig University, Zagazig, Egypt.

Received: 21 May 2021 Accepted: 21 December 2021

Published online: 06 January 2022

\section{References}

1. Kiadaliri AA. Global, regional, and national incidence, prevalence, and years lived with disability for 354 diseases and injuries for 195 countries and territories, 1990-2017: a systematic analysis for the Global Burden of Disease Study 2017. Lancet. 2018;392(10159):1789-858.

2. Lora A, Kohn R, Levav I, McBain R, Morris J, Saxena S. Service availability and utilization and treatment gap for schizophrenic disorders: a survey in 50 low-and middle-income countries. Bull World Health Organ. 2012:90:47-54B.

3. Laursen TM, Nordentoft M, Mortensen PB. Excess early mortality in schizophrenia. Annu Rev Clin Psychol. 2014;10:425-38.

4. Volkow Nora D. Substance use disorders in schizophrenia_clinical implications of co-morbidity. Schizophr Bull. 2009;35:469-72.

5. Croft J, Heron J, Teufel C, Cannon M, Wolke D, Thompson A, et al. Association of trauma type, age of exposure, and frequency in childhood and adolescence with psychotic experiences in early adulthood. JAMA Psychiatry. 2019;76(1):79-86.

6. Read J, van Os J, Morrison AP, Ross CA. Childhood trauma, psychosis and schizophrenia: a literature review with theoretical and clinical implications. Acta Psychiatr Scand. 2005;1 12(5):330-50.
7. Boullier M, Blair M. Adverse childhood experiences. Paediatr Child Health. 2018;28(3):132-7.

8. Alvarez-Alonso MJ, Jurado-Barba R, Martinez-Martin N, Espin-Jaime JC, Bolaños-Porrero C, Ordoñez-Franco A, et al. Association between maltreatment and polydrug use among adolescents. Child Abuse Negl. 2016;1 (51):379-89.

9. Shin $\mathrm{SH}$, Hong HG, Hazen AL. Childhood sexual abuse and adolescent substance use: a latent class analysis. Drug Alcohol Depend. 2010;109(1-3):226-35.

10. Ramiro LS, Madrid BJ, Brown DW. Adverse childhood experiences (ACE) and health-risk behaviors among adults in a developing country setting. Child Abuse Negl. 2010;34(11):842-55.

11. Dean AG. OpenEpi: open source epidemiologic statistics for public health, version 2.3.1. 2010. http://www.openepi.com

12. El-Gilany A, El-Wehady A, El-Wasify M. Updating and validation of the socioeconomic status scale for health research in Egypt. EMHJ. 2012;18(9):962-8

13. First MB, Williams JBW, Karg RS, Spitzer RL. User's guide for the structured clinical interview for DSM-5 disorders, clinician version (SCID-5-CV). Arlington: APA; 2016

14. Kay SR, Fiszbein A, Opler LA. The positive and negative syndrome scale (PANSS) for schizophrenia. Schizophr Bull. 1987;13(2):261.

15. Almuneef M, Qayad M, Aleissa M, Albuhairan F. Adverse childhood experiences, chronic diseases, and risky health behaviors in Saudi Arabian adults: a pilot study. Child Abuse Negl. 2014;38(11):1787-93.

16. Kikkert MJ, Barbui C, Koeter MWJ, David AS, Leese M, Tansella M, et al. Assessment of medication adherence in patients with Schizophrenia: the Achilles heel of adherence research. J Nerv Ment Dis. 2008;196(4):274-81.

17. Gold LH. DSM-5 and the assessment of functioning: the World Health Organization Disability Assessment Schedule 2.0 (WHODAS 2.0). Am Acad Psychiatry Law Online. 2014:42(2):173-81.

18. Mas-Expósito L, Amador-Campos JA, Gómez-Benito J, Lalucat-Jo L. The World Health Organization short disability assessment schedule: a validation study in patients with schizophrenia. Compr Psychiatry. 2012:53(2):208-16.

19. McLellan AT, Kushner H, Metzger D, Peters R, Smith I, Grissom G, et al. The fifth edition of the Addiction Severity Index. J Subst Abuse Treat. 1992:9(3):199-213.

20. Qassem T, Bishery Z, Asaad T, Omar A, Abdel Mawgood M. Profiles of neuropsychological dysfunctions with chronic heroin users. MD Degree Thesis. Faculty of Medicine, Ain Shams University; 2003.

21. IBM. SPSS statistics for windows, version 27. Armonk: IBM Corp: 2020 http://www-01.ibm.com/support/docview.wss?uid=swg27049428.

22. Schalinski I, Breinlinger S, Hirt V, Teicher MH, Odenwald M, Rockstroh B. Environmental adversities and psychotic symptoms: the impact of timing of trauma, abuse, and neglect. Schizophr Res. 2019:205:4-9.

23. Andrianarisoa M, Boyer L, Godin O, Brunel L, Bulzacka E, Aouizerate $B$, et al. Childhood trauma, depression and negative symptoms are independently associated with impaired quality of life in schizophrenia. Results from the national FACE-SZ cohort. Schizophr Res. 2017:185:173-81.

24. Larsson S, Andreassen OA, Aas M, Røssberg Jl, Mork E, Steen NE, et al. High prevalence of childhood trauma in patients with schizophrenia spectrum and affective disorder. Compr Psychiatry. 2013;54(2):123-7.

25. Üçok A, BIkmaz S. The effects of childhood trauma in patients with firstepisode schizophrenia. Acta Psychiatr Scand. 2007;116(5):371-7.

26. Popovic D, Schmitt A, Kaurani L, Senner F, Papiol S, Malchow B, et al. Childhood trauma in schizophrenia: current findings and research perspectives. Front Neurosci. 2019;21(13):274.

27. Vallejos M, Cesoni OM, Farinola R, Bertone MS, Prokopez CR. Adverse childhood experiences among men with schizophrenia. Psychiatr Q. 2017:88(4):665-73.

28. Rosenberg SD, Lu W, Mueser KT, Jankowski MK, Cournos F. Correlates of adverse childhood events among adults with schizophrenia spectrum disorders. Psychiatr Serv. 2007;58(2):245-53.

29. Rajkumar RP. The impact of childhood adversity on the clinical features of schizophrenia. Schizophr Res Treat. 2015. https://doi.org/10.1155/2015/ 532082.

30. Duhig M, Patterson S, Connell M, Foley S, Capra C, Dark F, et al. The prevalence and correlates of childhood trauma in patients with early psychosis. Aust N Z J Psychiatry. 2015:49(7):651-9. 
31. Bendall S, Alvarez-Jimenez M, Hulbert CA, McGorry PD, Jackson HJ. Childhood trauma increases the risk of post-traumatic stress disorder in response to first-episode psychosis. Aust N Z J Psychiatry. 2012;46(1):35-9.

32. Andrianarisoa M, Boyer L, Godin $\mathrm{O}$, Brunel L, Bulzacka E, Aouizerate $B$, et al. Childhood trauma, depression and negative symptoms are independently associated with impaired quality of life in schizophrenia. Results from the national FACE-SZ cohort. Schizophr Res. 2017:185:173-81.

33. Schenkel LS, Spaulding WD, DiLillo D, Silverstein SM. Histories of childhood maltreatment in schizophrenia: relationships with premorbid functioning, symptomatology, and cognitive deficits. Schizophr Res. 2005;76(2-3):273-86.

34. Gil A, Gama CS, de Jesus DR, Lobato MI, Zimmer M, Belmonte-de-Abreu P. The association of child abuse and neglect with adult disability in schizophrenia and the prominent role of physical neglect. Child Abuse Negl. 2009;33(9):618-24

35. Hirt V, Schalinski I, Rockstroh B. Decoding the impact of adverse childhood experiences on the progression of schizophrenia. Ment Health Prev. 2019:13:82-91.

36. Daalman K, Diederen KM, Derks EM, van Lutterveld R, Kahn RS, Sommer IE. Childhood trauma and auditory verbal hallucinations. Psychol Med. 2012;42(12):2475

37. Yildirim MH, Yildirim EA, Kaser M, Guduk M, Fistikci N, Cinar O, et al. The relationship between adulthood traumatic experiences and psychotic symptoms in female patients with schizophrenia. Compr Psychiatry. 2014;55(8):1847-54.

38. Thompson JL, Kelly M, Kimhy D, Harkavy-Friedman JM, Khan S, Messinger JW, et al. Childhood trauma and prodromal symptoms among individuals at clinical high risk for psychosis. Schizophr Res. 2009;108(1-3):176-81.

39. Álvarez MJ, Roura P, Osés A, Foguet Q, Solà J, Arrufat FX. Prevalence and clinical impact of childhood trauma in patients with severe mental disorders. J Nerv Ment Dis. 2011;199(3):156-61.

40. Kocsis-Bogár K, Mészáros V, Perczel-Forintos D. Gender differences in the relationship of childhood trauma and the course of illness in schizophrenia. Compr Psychiatry. 2018;82:84-8.

41. Longden E, Sampson M, Read J. Childhood adversity and psychosis: generalized or specific effects? Epidemiol Psychiatr Sci. 2016;25(4):349-59.

42. Baudin G, Godin O, Lajnef M, Aouizerate B, Berna F, Brunel L, et al. Differential effects of childhood trauma and cannabis use disorders in patients suffering from schizophrenia. Schizophr Res. 2016;175(1-3):161-7.

43. Lecomte T, Spidel A, Leclerc C, MacEwan GW, Greaves C, Bentall RP. Predictors and profiles of treatment non-adherence and engagement in services problems in early psychosis. Schizophr Res. 2008;102(1-3):295-302.

44. Anda RF, Felitti VJ, Bremner JD, Walker JD, Whitfield CH, Perry BD, et al. The enduring effects of abuse and related adverse experiences in childhood. Eur Arch Psychiatry Clin Neurosci. 2006;256(3):174-86.

45. Lasalvia A, Tosato S, Brambilla P, Bertani M, Bonetto C, Cristofalo D, et al. Psychosis Incident Cohort Outcome Study (PICOS). A multisite study of clinical, social and biological characteristics, patterns of care and predictors of outcome in first-episode psychosis. Background, methodology and overview of the patient sample. Epidemiol Psychiatr Sci. 2012;21(3):281-303.

46. Margolese HC, Malchy L, Negrete JC, Tempier R, Gill K. Drug and alcohol use among patients with schizophrenia and related psychoses: levels and consequences. Schizophr Res. 2004;67(2-3):157-66.

47. Asaad TA, Okasha TA, El-Khouly GA, Azim KA. Substance abuse in a sample of Egyptian schizophrenic patients. Addict Disord Their Treat. 2003;2(4):147-50.

48. Swartz MS, Wagner HR, Swanson JW, Stroup TS, McEvoy JP, Canive $J M$, et al. Substance use in persons with schizophrenia: baseline prevalence and correlates from the NIMH CATIE study. J Nerv Ment Dis. 2006;194(3):164-72.

\section{Publisher's Note}

Springer Nature remains neutral with regard to jurisdictional claims in published maps and institutional affiliations.

\section{Submit your manuscript to a SpringerOpen ${ }^{\circ}$ journal and benefit from:}

- Convenient online submission

- Rigorous peer review

- Open access: articles freely available online

- High visibility within the field

- Retaining the copyright to your article

Submit your next manuscript at $\boldsymbol{\nabla}$ springeropen.com 